\title{
THE INHERENT PROBLEMS OF LEgal TRANSLATION: \\ THEORETICAL ASPECTS
}

\author{
Edgardo Rotman
}

\section{INTRODUCTION}

A theory of legal translation can be overwhelmingly vast. Leading translation theoreticians have asserted that all communication is translation.' This view expands translation theory into a comprehensive theory of language. ${ }^{2}$ On the other hand, the consideration of the close relation between language and the law carries the risk of transforming legal translation theory into a general theory of law.

The relation between language and the law is so intimate that it is not farfetched to say that law is essentially language. Law may be expressed in nonverbal forms, such as traffic lights, sirens or tolling bells. Also, customary law, as a "language of interaction," is not a negligible part of the legal

* Edgardo Rotrran is the Foreign and Intemational Law librarian at the University of Miami School of Law, where he also teaches international legal research, international moot court, prison law and post-conviction remedies, and comparative criminal law. He also taught at the Universidad de Buenos Aires, Universidad del Salvador (Argentina), and Boston University, and was a visiting scholar at the Harvard Law School. He is a member of the Buenos Aires and the Massachusetts bars, and has practiced law both in Argentina and the United States. He is an expert in Western European and in Latin American law. He is the author of BEYOND PUNISHMENT: A NEw View on the ReHabilttation of Criminal OfFEnders (Greenwood Press 1990) and The Failure of Reform, in THE OXFORD HISTORY OF THE PRISON (Oxford University Press 1995) (a history of American prisons from 1865 to 1965). He has published three books and more than twenty-five articles in leading American, Latin-American, German and French law journals.

The author is thankful to Leandro Rotman, Viviana Zelizer, Dionne Wilson, Samantha Healy and Charles François, who read the manuscript and made valuable comments.

An earlier version of this article was presented as a paper at the American Association of Law Libraries Annual Meeting (Seattle, July 1994).

1. For Octavio Paz, language itself is essentially a translation: "[f]irst from the nonverbal world and then because each sign and each phrase is a translation of another sign, another phrase." Octavio Paz, Translation: Literature and Letters, in THEORIES OF TRANSLATION: AN ANTHOLOGY OF ESSAYS FROM DRYDEN TO DERRIDA 154 (R. Schulte and J. Biguenet eds., The University of Chicago Press 1992). "As language itself is a translation, . . 'translation is translation for a second time ... the process of translating comprises the whole secret of human understanding of the world and of social communication...." Id at introduction, quoting the German philosopher Hans Georg Gadamer.

2. Loón Robel, Théorie Générale de la Traduction et Métamorphismes Rythmiques, in THEORY AND PRACTICE OF TRANSLATION 93, 95 (Grähs, Korlen and Malmberg eds., Peter Lang 1978). Mr. Robel identifies the theory of translation with the theory of meaning. Bertil Malmberg underscores the linguistic nature of translation theory in the introduction to this same book. Id. at 11 .

3. Lon L. Fuller, Human Interaction and the Law, 14 AM. J. JURIS. 1, 2-3 (1969). 
phenomenon. Yet, law is substantially formulated through written language. Law and language are structurally similar. They are generated through social practices, resulting in organized and more or less formalized communication systems, in the sense that they are both governed by their own rules of creation and reproduction.

The relation between law and language can significantly broaden the scope of legal translation theory. For instance, a group of legal theoreticians took translation as a model for legal interpretation and for justice itself. ${ }^{4}$ Translation is seen by James Boyd White as "a set of practices that can serve as an ethical and political model for the law and, beyond it, as a standard of justice." Lawrence Lessig draws on the practice of translation to formulate a general interpretive legal model and Clark Cunningham speaks of the law as a language and of the lawyer as a translator. ${ }^{6}$

Given the breadth of this theoretical field, this article addresses but one of the components of translation theory-the "description and analysis of operations."7 In this regard, this article will draw conclusions from the author's experiences in legal translation, while attempting to underscore the significance of the field for professional translators.

\section{DETERMining THE SCOPE OF Legal Translation}

Roman Jakobson, a leading linguist and noted expert in the subject of translation, defined translation as "the interpretation of verbal signs by means of some other language." Through this process of translation, texts in one language are transformed into texts in another language with the same meaning.

The nature and scope of translation depends on the nature and scope of the translated materials. These materials range from the isolated words in a language dictionary to the complex network of sentences of philosophical texts. Furthermore, translations can convey the supposedly plain, unequivocal, and

4. See generally James B. White, Justice as TRANSLATION: AN ESSAY IN CULTURAL AND Legal CRITICISM (The University of Chicago Press 1990). See also Clark D. Cunningham, A Tale of Two Clients: Thinking About Law as Language, 87 MICH. L. REV. 2459 (1989) and Lawrence Lessig, Fidelity in Translation, 71 TEX. L. REV. 1165 (1993).

5. WHITE, supra note 4 , at 258.

6. Lessig, supra note 4 , at 2483 .

7. LOUIS G. Kelly, THE TRUE INTERPRETER: A History OF TRANSLATION THEORY AND PRACTICEIN THE West 1 (St. Martin's Press 1979). Mr. Kelly points out that a complete theory of translation "has three components: specification of function and goal; description and analysis of operations; and critical comment on relationships between goals and operations." Id.

8. Id. (quoting Roman Jakobson). 
verifiable laws of the natural sciences, as well as the subtle emotions, mind sets, and personal insights of poetry. ${ }^{9}$

In legal translation the demands of precision are greater than in literary translation. The translator must comply, not only with the rules of the foreign language, but also, with the rules of the foreign legal system. Legal translation has its own rules and procedures, which have to be added to those already existing in the translation of nonlegal texts. Everyday language already implies a formalized way of communication, while legal language introduces a supplementary system of formalization.

Although legal translation demands precision and certainty, it is bound to use abstractions, whose meanings derive from particular changing cultural and social contexts. These contexts generate a certain degree of ambiguity, which increases when the legal cultures and systems are vastly different from each other. To translate a text from the language of a civil law country to the language of another civil law country is generally less complicated than to translate the same text to the language of a common law country. Difficulties increase when the translation is from non-Western legal systems, such as the Hindu or Islamic, which differ substantially from the system of the target language. ${ }^{10}$

Translators must be familiar with the legal culture of the target language in order to reformulate an equivalent meaning through what they judge to be the most appropriate linguistic and legal expressions. Persons speaking the same language, but belonging to different legal systems, can have greater "translational" problems than persons speaking different languages under the same legal system. For example, a Scotch lawyer who has to translate terms from a text of American corporate law might encounter greater difficulty than a German Swiss translating a French text on Swiss law. ${ }^{11}$

Greater difficulties arise when a legal institution is foreign to the legal system of the target language. That was the case of the word "trust" in French law before $1990 .^{12}$ The legal translator is more rigidly bound to specialized knowledge than the translator of everyday language or humanities. ${ }^{13}$

9. Peter W. Schroth, Legal Translation, 34 AM. J. CoMP. L. 47, 49 (1986 Supplement). Mr. Schroth indicates that computer-programmed translations are "most nearly satisfactory when the subject matter is most nearly independent of culture, as in chemistry or mathematics." Id.

10. HENRY P. DEVRIES, ForEIGN LAW AND THE AMERICAN LAWYER: AN INTRODUCTION TO THE CIVIL LAW METHOD AND LANGUAGE xvii (Columbia University 1969).

11. Tomasz Gizbert-Studnicki, Das Problem des Übersetzens und das juristische Weltbild, in ÜBERSETZEN, VERSTEHEN, BROCKEN BAUEN 309 (Erich Schmidt Verlag 1993).

12. Draft legislation was presented, in the form of an avant-projet, introducing a trust equivalent, la fiducie, into French law in 1990. In February 1992, the Ministry of Justice proposed a bill modifying the civil code for that purpose. See Madeleine C. Cumyn, L'avantprojet de loi relatif a la fiducie, un point de vue civiliste d'outre-atlantique, in RECUEIL DALLOZ SIREY 117-120 (14ème cahier-chronique 1992).

13. Gizbert-Studnicki, supra note 11, at 313. 
It is important to distinguish between the normative language of the law (statute, custom, or judicial doctrine) and the language of the jurist, who thinks or writes about the law. ${ }^{14}$ In the first instance, the translator is more constrained by the words of the positive, obligatory law. In the second situation, the language of the jurist (law review articles, treatises, or monographs) is given more latitude to translate the spirit of the message, thus, diminishing the bondage to literal expression.

Within the language of lawyers one should further distinguish between an internal and an external view of the law. The constraints are greater when lawyers interpret a particular rule of positive law than when they examine legal issues as part of global social issues.

A major point of contention in translation is the notion of "translatability" (or "untranslatability"). ${ }^{15}$ Poetry, in which the words are so blended with the message, can be very difficult to translate without losing its original flavor. Such an example can possibly justify some assertions of "untranslatability." Within the sphere of the law, where vital social problems are at play, transfrontier communication is essential and the mere idea of "untranslatability" becomes extremely harmful.

Human problems are universal and common. The internationalization of basic human issues (economy, crime, health, and environment) has increased cooperation among countries. The cutting edge of legal progress is in the harmonization of laws and eventual unification. Translation can help to build a universal legal language aimed towards resolving universal legal problems.

\section{SignificancE of LEgal TRANSLATION}

The significance of translation is multifold. Translation allows different cultures to connect, interact, and enrich one another. So far as translation takes an element from one particular cultural system and introduces it into another, it serves as a cultural "pollenizer." As Ralph Linton points out: "The comparatively rapid growth of human culture as a whole has been due to the ability of all societies to borrow elements from other cultures and to incorporate them into their own."16 Translation also contributes to the resolution of medical, political, and other professional, social, and individual problems.

14. The distinction between language of the law and language of the jurists was first employed by Kelsen and later developed by the Swedish philosopher I. Hedenius, and by Wroblewski. See JuAN-RAmon CAPfJ 33 (Ediciones Ariel 1968).

15. Frederic WLL, Translation Theory and Practice: Reassembling the ToWer 187 (The Edwin Mellen Press 1993). For Mr. Will, "untranslatability" is a "nonconcept" that can never be proven, because "our only legitimate way of querying whether untranslating exists, by its nature precludes the discovery of what it seeks." Id.

16. Ralph Linton, ThE StUdy OF MAN: AN INTROduction 324 (New York 1936). 
The general importance of legal language is shared by legal translation. The significance of legal language is made apparent if one considers its connection to human action. Words are not only instruments of expression, but also instruments of action. The language of the law is not merely the denotation of objects, but it is the language of future actions. It is, in the terms of Richard M. Hare, prescriptive. ${ }^{17}$ Legal language constitutes a projection into the future that permits one to anticipate and predict human behavior with the degree of certainty necessary for social life. ${ }^{18}$

In the field of international law, the significance of legal translation is evident in many respects. Since the right of states to communicate in their own language has replaced the use of diplomatic languages such as French or Latin, translation has become more important than ever in international law. Yet, very little attention has been devoted to language in international law and there are virtually no rules regarding the use of interpreters and language specialists in international relations.

The danger of the existing communication gap among nations is discussed by Christopher $B$. Kuner in an article reviewing various misunderstandings in the recent Persian Gulf crisis. ${ }^{19}$ A hilarious example of a communication gap is President Jimmy Carter's visit to Poland, during which his wish to "learn opinions and understand your desires for the future" was erroneously translated as "I desire the Poles carnally."

Translation also matters greatly for international law in the area of international organizations. For example, the plurality of languages in the European Community creates a serious challenge to communication. ${ }^{21}$ Unlike conventional international law, much of European Community law is directly and immediately applicable to individual citizens of its member states who, in turn, must have access to this law in a language they understand. ${ }^{22}$ It is a situation similar to that of multilingual nations, such as Belgium, Switzerland, and Canada. The European Community has the world's largest translation service. Significantly, in 1987 the Commission of the European Community spent about one-third of its two billion dollar annual budget on translation operations. ${ }^{23}$

17. Richard Mervyn Hare, The Language of Morals 1-14 (Clarendon Press 19.52).

18. Sebastian Soler, Las Palabras de La LEY 15 (Fondo de Cultura Económica 1969).

19. Christopher B. Kuner, Linguistic Equality in International Law: Miscommunication in the Gulf Crisis, 2 IND. INT'L \& COMP. L. REV. 175 (1991).

20. Paul Simon, The TONGUE-Tied american: Confronting the Foreign Language CRISIS 8-9 (Continuum 1980).

21. Hélène Bauer-Bernet, Le Multilinguisme du Droit de la Communauté Européenne, in LANGUAGE DU DROIT ET TRADUCTION: EsSAIS DE JURILINGUISTIQUE 189 (Jean-Claude Gémar, ed., Linguatech-Conseil de la Langue Française 1982).

22. Robert Huntington, European Unity and the Tower of Babel, 9 B.U. INT'L L.J. 321 , 327 (1992).

23. Id. at $325-26$. 
Comparative law is largely dependent upon translation. ${ }^{24}$ The availability of foreign legal materials through legal translation enriches the range of possible solutions by connecting readers to foreign legal cultures. In addition, "borrowing from abroad has become a recognized legislative practice for most contemporary states."25

As the United States evolves into a multilingual society, legal translation has become vital to American law firms. A growing number of American clients, who do not know English, require legal services. Meanwhile, the expansion of transborder law firms demands communication with an increasingly international clientele. Moreover, foreign investment in the United States intensifies the need for translation of a larger variety of documents. ${ }^{26}$

\section{Evaluating Legal Translations}

An important aspect of legal translation theory is how to determine the quality of a translated text. Fidelity in translation includes not only fidelity to text, but also preservation of the meaning of the context. An efficient translator must track any change of context between the writing of the text and its interpretation. As Lawrence Lessig states, "meaning is made from something in the foreground (text) and something in the background (context). To preserve meaning both grounds must be tracked."27

The translator must understand both the legal culture from which the source text derives and the legal culture to which the target text will apply. In legal translation this often includes understanding complex legal theoretical contexts.

If the target text belongs to a very different legal system, it will be necessary to reach an equivalent meaning by using a high degree of explanation, flexibility, and creativity. Translators must find equivalent legal terms in the target language or terms that have an equivalent legal function. Translators may even encounter terms for which there is no equivalent legal meaning. ${ }^{28}$ In such

24. Schroth, supra note 9, at 53. Mr. Schroth points out that comparative law always involves translation even when the comparison is between two legal systems that share the same language.

25. Peter H. Sand, The Harmonization of African Law, in CURRENT TRENDS IN AFRICAN Legal GeOGRAPHY: ThE INTERfusion OF LEGAL Systems 126 (Guiffre 1974). See also José

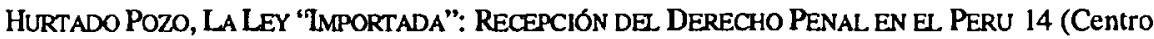
de Estudios de Derecho y Sociedad 1979). Prof. Hurtado explains how law, as part of culture, is transferred from one social group to another.

26. George P. Rimalower, Translating and Interpreling: A Growing Law Firm Need, 18 LAW PRAC. MGMT. 34, 34 (1992).

27. Lessig, supra note 4 , at $1177-78$.

28. DENNIS R. KLINCK, THE WORD OF THE LAW 25 (Carleton University Press 1992). Mr. Klinck illustrates this point with a hypothesis based on Whorf's conclusion that the Hopi language lacks a future tense. The Hopi law would therefore lack a doctrine of "future interests," which would make a translation of such concepts into Hopi language extremely difficult. He also uses 
situations they may have to resort to neologisms or to the repetition of the word in its original language with an appropriate explanation or definition incorporated into the text or listed in a glossary.

The notion of equivalence does not mean simple replication of words from the original text, but rather to construct the text in the target language so as to "carry the same force or significance as the text in the source context."29 Fidelity demands accounting for context, whether the contextual distance is temporal or geographical. In translating a term from the law of a country belonging to a certain legal system into the language of a country belonging to a different system, one has to find a way to neutralize, or at least minimize, the change of context.

\section{TRANSLATION IN ACTION}

As Maurice Gravier indicates, the practice of translation has unquestionably preceded the speculation of theoreticians. Gravier recognizes, however, that a lucid work of translation demands reflection on the task, a continuing refinement of method, and avoidance of routine approaches. ${ }^{30}$

The problems of translation methodology cannot be resolved in the abstract. Working with specific instances of translations, Lawrence Lessig maintains "we see that the differences in method track differences in the purpose or function of translation, more than they track any useful philosophical commitment to one method or the other."31

Translating legal and social science texts requires two basic skills. First, of course, solid linguistic knowledge of both language systems is necessary. But this alone is not sufficient. One also needs a thorough knowledge of the subject in the legal or social systems concerned. These two conditions make possible the translation of a scientific text even when the contents are extremely complex. The difficulty lies in the fact that concepts of law and legal policy are closely related to the respective language systems. Through the translation from one language system to another, it is very easy to alter the information provided in the text. A good translation maintains both the integrity of the information and the nuances inherent in each language.

These theoretical arguments are extracted from the author's personal experiences as a translator. The specific problems to be addressed arose from the author's translation of two articles from German to Spanish: THE AIM OF CRIMINAL PUNISHMENT AND THE REFORM OF CRIMINAL LAW by Klaus Roxin and

other examples of cases in which legal translation demands that a "new word should be coined, or the word from the first language simply imported into the second."

29. Lessig, supra note 4, at 1201.

30. Maurice Gravier, Pedagogie de la Traduction, in THEORY AND PRACTICE OF Translation 203 (Grähs, Korlén and Malmberg eds., Peter Lang 1978).

31. Lessig, supra note 4 , at 1165. 
ECONOMIC CRIME AND ECONOMIC CRIMINAL LAW IN THE UNITED STATES AND THE FEDERAL REPUBLIC OF GERMANY by Klaus Tiedemann. The ideas here discussed are also drawn from the author's experience in translating a text on habeas corpus from English to Spanish for Hispanic prisoners in Massachusetts.

One preparatory task of a translation into English is to dissect the long sentences that are common in the German language, and to a lesser extent, in Spanish and other Romance languages. This segmenting of the source-text sentence is a necessary but risky procedure that can easily alter its meaning.

The first requirement is to understand the structure of the language through a grammatical approach (including phonology, morphology, and syntax) and the semantical analysis of the combination and grouping of words into sentences and of sentences into paragraphs. As W. H. Snyder affirms, "if we can devise rules for the structure of a language, then we can also derive rules for the transposition of the structure of one language to that of another." 32

The approach taken in translating the above mentioned articles was to first identify the main parts of the sentence, such as the subject, predicate, objects, attributes, adverbs and secondary sentences (nebensaetze in German) and their functions. Because the legal system deals mainly with human behavior, the central role of the verb in the sentence is intensified in legal translation.

After having analyzed the sentence, it was necessary to identify certain complex word contents. In social sciences, such concepts are a central mode of communication. For example, in the Roxin essay, it was necessary to explain the meaning of the word Entmoralisierung in the phrase "Entmoralisierung des Strafrechts," meaning that criminal law should dispense of private moral issues in its regulations. Without explanation, the word Entmoralisierung could easily have been interpreted in that context as a criminal law that was "against morality" or as advocating the "elimination of morality" in criminal law, which would have certainly not conveyed the true meaning of the text. Another case of a word whose legal significance requires careful explanation in translated text is "common law marriage." As Keith Rosenn points out, the full legal significance is not given by the words concubinato or union de hecho, terms that refer to informal unions. ${ }^{33}$

There were also difficulties in translating legal terms connected to particular legal theories. In German criminal law, there are words such as Tipizitaet (typicality), Tatbestandsmaessigkeit (adequacy of conduct to a legal definition), and Tatschuld (responsibility for the fact), which can be understood only through a thorough knowledge of the theoretical system in which they were

32. William H. Snyder, Linguistics and Translation, in TRANSLATION SPECTRUM: Essays IN Theory AND PRaCtice 128 (M.G. Rose ed., State University of New York Press 1981).

33. Keith S. Rosenn, Review of Dahl's Law Dictionary. Diccionario Juridico, 24 U. MIAMI INTER-AM. L. REV. 607, 615 (1993). 
developed. Likewise, to grasp the full significance of the word "injunction," it is necessary to have fully understood the doctrine of equitable remedies. ${ }^{34}$

Often words lose their ordinary significance and have to be translated in their more specific legal meaning. The literal translation into Spanish of "to challenge" would be desafiar, if the narrower legal technical meaning were mistakenly ignored. As a result, in the translation of the habeas corpus text, the word "challenge" was not translated as desafio, but rather as impugnación or ataque. The Spanish word culpable does not necessarily mean "guilty" in the technical sense of an admission of guilt in American criminal procedure, but can also mean being "culpable" or "blameworthy" in a more general sense. ${ }^{35}$

When ordinary events, objects, and concepts enter the realm of the legal world, they often undergo significant transformations. For example, the word "death" has a special technical meaning when it becomes an element of a legal norm, as opposed to the theological or common meaning of the word. ${ }^{36}$ Another example is the word "person," which has a specific legal meaning different from the common one. ${ }^{37}$

The need to deal with this specialized terminology shows that only a translator acquainted with both legal systems can undertake the task. Nonspecialized translators, even with the highest degree of linguistic knowledge, are simply unable to translate legal texts such as the examples previously mentioned. Furthermore, this type of translation requires not only knowledge of the law in general, but also solid acquaintance with the specialized field, its doctrines, and particular theoretical models.

One should also take into account that words are not mere expressions to distinguish objects, but that these words and terms have a systemic meaning. A good translation should, as far as possible, maintain the measure and the style of the foreign author while respecting the rules of the target language. Legal essays

34. Id. at 614 .

35. Cunningham, supra note 4 , at 2464 . The author believes that to understand what "non-guilty" means, "the client would need at a minimum to know about the presumption of innocence, the procedural role of arraignment, the elements of the two different criminal charges against him, the possibility of suppressing key evidence, and the effect of such suppression on the state's ability to carry its burden of proof." Id. at 2483. Mr. Cunningham points out that the need of translating would have been the same if the client spoke English, which would support his thesis of lawyering as translation. Id

36. For a full discussion of the various concepts of death, see REVEREND ALBERT S. MORACEEWSK AND J.STUART SHOWALTER, DETERMINATION OF DEATH: THEOLOGICAL, MEDICAL, ETHiCAL, AND Legal Issues (The Catholic Health Association of the United States 1982). On the legal concept of death, see DEFINING DEATH: A REPORT ON THE MEDICAL, LEGAL AND ETHICAL ISSUES IN THE DETERMINATION OF DEATH (President's Commission for the Study of Ethical Problems in Medicine and Biomedical and Behavioral Research 1981).

37. Francisoo Ferrara, Teoria de las Personas Juridicas 318 (1929), classifies the various meanings of the word "person" as anthropological (i.e., human being), theologicalphilosophical (i.e., rational being), and legal (i.e., a being possessing the capacity to act legally). 
contain a great amount of argumentative thought and a very specific message that a translation must seek to preserve.

Translation functions as a "pollenizer" of cultures, enriching one culture with the insights of another. Moreover, legal translation serves as a bridge for understanding between nations, facilitating the resolution of vital human issues. Such a significant tool deserves broader recognition from both linguists and jurists alike. 